\title{
Estimating the weight of a snow cover using only meteorological factors
}

\author{
Kenji Shinojima ANd Hiroshi HaRada \\ Tohoku Electric Power Company Incorporated, Applied Technology Research and Development Center, Snow and Ice Technology Section \\ Aobaku, Nakayama 7-2-1, Sendai 981, Japan
}

\begin{abstract}
We compute the weight of the snow cover as a function of the daily quantity of precipitation and daily melting using only data from the Automated Meteorological Data Acquisition System (AMeDAS), which is used widely in Japan. The correlation between long-term measurements and meteorological data in AMeDAS factors was computed by statistical methods from the Forestry and Forest Product Research Institute, Tokamachi Experiment Station, in Niigata Prefecture, using data for 11 winter seasons (1977-87) .

The daily quantity of melting is expressed with a three-day moving average of degree days. The coefficient of correlation between the daily groups of each value of the 1323 days during the 11 winter seasons was 0.986 with a standard deviation of $\pm 590 \mathrm{~N} \mathrm{~m}^{-2}$. Thus, if air temperature and precipitation can be obtained for an area, the weight of the snow cover can be estimated with confidence.
\end{abstract}

\section{INTRODUCTION}

The hard work of removing roof snow has been regarded as a part of life in the heavy snow regions of Japan, and people incur labour and expense for snow removal. During the development of various apparatus for removing roof snow, it became necessary to express snow weight and its daily variance as accurately as possible in order to quantify roof snow to be removed during the winter season.

At present, we can obtain long-term meteorological data on air temperature, precipitation, wind speed and direction, sunlight hours, and snow depth with AMeDAS, which automatically observes normal meteorological conditions at many points over a broad area. We have assumed that estimates of the weight of the snow cover can be obtained using only AMeDAS.

We use a computing method which depends on the difference between the daily quantities of precipitation and melting, in spite of the difficulties in estimating daily snowmelt.

In order to estimate glacier ablation and snowmelt runoff to rivers or streams, methods based on either the energy balance of the snow cover or degree days have been proposed (Kubota and others, 1978; Takahashi and others, 1981; Kojima and others, 1983; Ishikawa and others, 1985). Heat-balance methods may be accurate, but detailed data over a broad area are difficult to obtain. Functional relationships may estimate long-term snowmelt but can produce unsatisfactory short-term results. An estimate of snowmelt using only degree days is generally improved by increasing the integration period. The suitable integration period depends upon the desired confidence in the estimate of the daily snowmelt variable.

\section{METHODS}

To estimate the weight of the snow cover using only AMeDAS data, the correlation between long-term measurements for the weight of the snow cover and meteorological factors taken from AMeDAS data observed at the same place must be obtained by statistical methods. The statistical correlation was obtained by the trial and error method using values of the weight of the ground snow cover and meteorological data from 11 winter seasons (1977-87) observed at the Ministry of Agriculture, Forestry and Fishery's Forestry and Forest Product Research Institute, Tokamachi Experiment Station, in Niigata Prefecture (Tokamachi Experimental Site and Disaster Prevention Forest Laboratory, 1986, 1987).

The total weight of snow cover was obtained by summing the difference between the daily quantities of snowmelt and precipitation. This was computed from the beginning of snowfall each year for observations over a period from $0900 \mathrm{~h}$ of the $i^{\text {th }}$ day to $0900 \mathrm{~h}$ of the $(i+1)^{\text {th }}$ day. We determined the daily quantities of precipitation and melting by the following methods.

First, since precipitation in the air temperature range of $0^{\circ}-2^{\circ} \mathrm{C}$ may assume the forms of snow, sleet, hail or rain, it was necessary to evaluate the quantity of precipitation according to its form (Tamura, 1990; Hasemi, 1991). Using the data of Tokamachi Experiment Station during the 1978/79-1984/85 winter seasons, we assumed that the precipitation may be regarded as snow below $0^{\circ} \mathrm{C}$ and as rain above $2^{\circ} \mathrm{C}$. Furthermore, the ratio of snowfall was assumed to decrease linearly with increasing air temperature in the range of $0^{\circ}-2^{\circ} \mathrm{C}$. Consequently, the precipitation quantity of snow at 
these temperatures was computed for the $i^{\text {th }}$ day from

$$
w_{\mathrm{fi}}=w_{\mathrm{fi}}{ }^{\prime}\left(1-T_{\mathrm{a} i} / 2\right),
$$

where $T_{\mathrm{a} i}$ is daily mean air temperature and $w_{\mathrm{fi}}{ }^{\prime}$ is total daily precipitation quantity at $0^{\circ}-2^{\circ} \mathrm{C}$.

Next, the daily quantities of snowmelt were assumed to be the difference between the total weight of snow cover measured at $0900-1000 \mathrm{~h}$ on two sequential days without snowfall or rainfall. Therefore, the relationship between the daily weight reduction of the snow cover and other meteorological factors may be considered statistically. However, it was assumed that the daily precipitation quantity due to rainfall drained away from the snow cover within a day, and that snowmelt did not occur on the day of snowfall. Further, the previous and following days on which snow depth was zero were not included in the data for obtaining daily snowmelt because of the uncertainty of disappearance time, and rain days with precipitation below $5 \mathrm{~mm} \mathrm{~d}^{-1}$ were adopted to compensate for insufficient data. The timing of the actual runoff from the snow cover is usually delayed by the depth and the stratigraphy of snow cover. Though the daily quantity of snowmelt is not strictly the same as daily quantity of runoff, these values were treated the same for the sake of convenience.

Snowmelt is linked to the energy balance of the snow cover as determined by the various energy fluxes. However, in the case of long-term snowmelt, the quantity of snowmelt may be approximately expressed as a function of daily mean air temperature.

On the basis of the above results, attempts were made to find a functional formula for snowmelt quantity which has significant statistical correlation by using the trial and error method, and incorporating daily mean air temperature, daily maximum air temperature, daily minimum air temperature, daily mean wind speed and daily sunlight hours, etc. As a result, the relationship between the three-day moving accumulation of snowmelt and the three-day moving degree days (moving accumu-

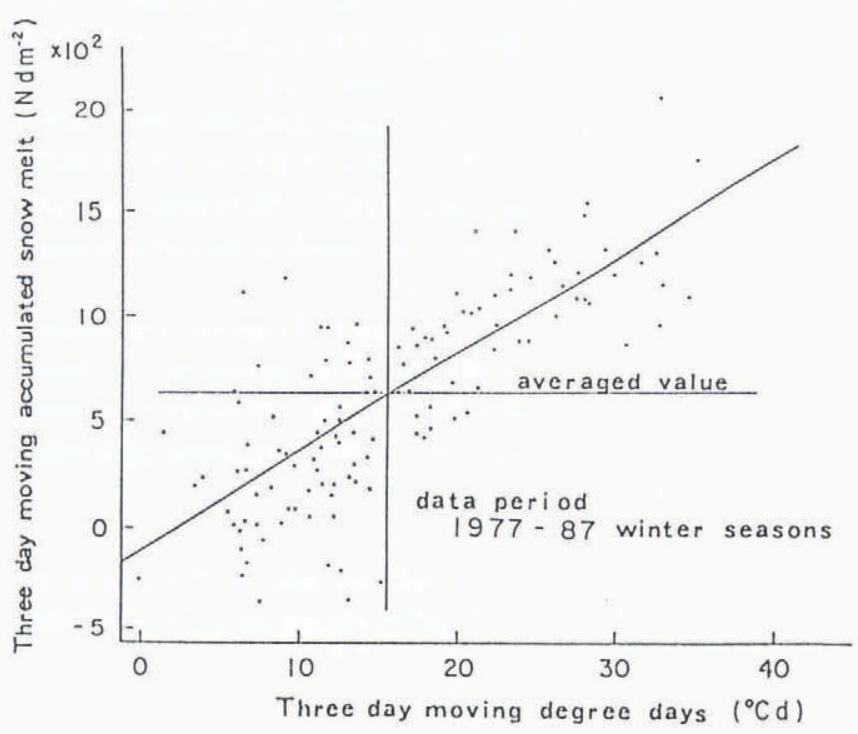

Fig. 1. Relation between the daily quantity of snowmelt and the daily mean air temperature measured at the Forestry and Forest Product Research Institute, Tokamachi Experiment Station. lated positive daily mean air temperature for three days) was obtained with a correlation coefficient of 0.797 .

Figure 1 shows the relationship between the three-day moving accumulation of snowmelt and the three-day moving degree days.

The formula obtained approximately from these data is

$$
\sum_{j=i-2}^{i} w_{\mathrm{m} j}=46.0 \sum_{j=i-2}^{i} T_{\mathrm{a} j}-122.0 \text {, }
$$

where $w_{\mathrm{m} j}$ is the daily quantity of melt on the $i^{\text {th }}$ day. Accordingly, the daily quantity of melt is computed according to

$$
w_{\mathrm{m} i}=\sum_{j=i-2}^{i} w_{\mathrm{m} j} / 3
$$

and the weight of the snow cover is expressed for $0 \leq T_{\mathrm{a} i} \leq 2^{\circ} \mathrm{C}$ as

$$
W_{\mathrm{s} n}=\sum_{i=1}^{n-1}\left\{w_{\mathrm{fi}}{ }^{\prime}\left(1-T_{\mathrm{a} i} / 2\right)-\left(46.0 \sum_{j=i-2}^{i} T_{\mathrm{a} j}-122.0\right) / 3\right\},
$$

where $W_{\mathrm{sn}}$ is the weight of the snow cover on the $n^{\text {th }}$ day.

When $T_{\mathrm{a} i} \leq 0^{\circ} \mathrm{C}$

$$
W_{\mathrm{s} n}=\sum_{i=1}^{n-1}\left\{w_{\mathrm{f} i}-\left(46.0 \sum_{j=i-2}^{i} T_{\mathrm{a} j}-122.0\right) / 3\right\} \text {. }
$$
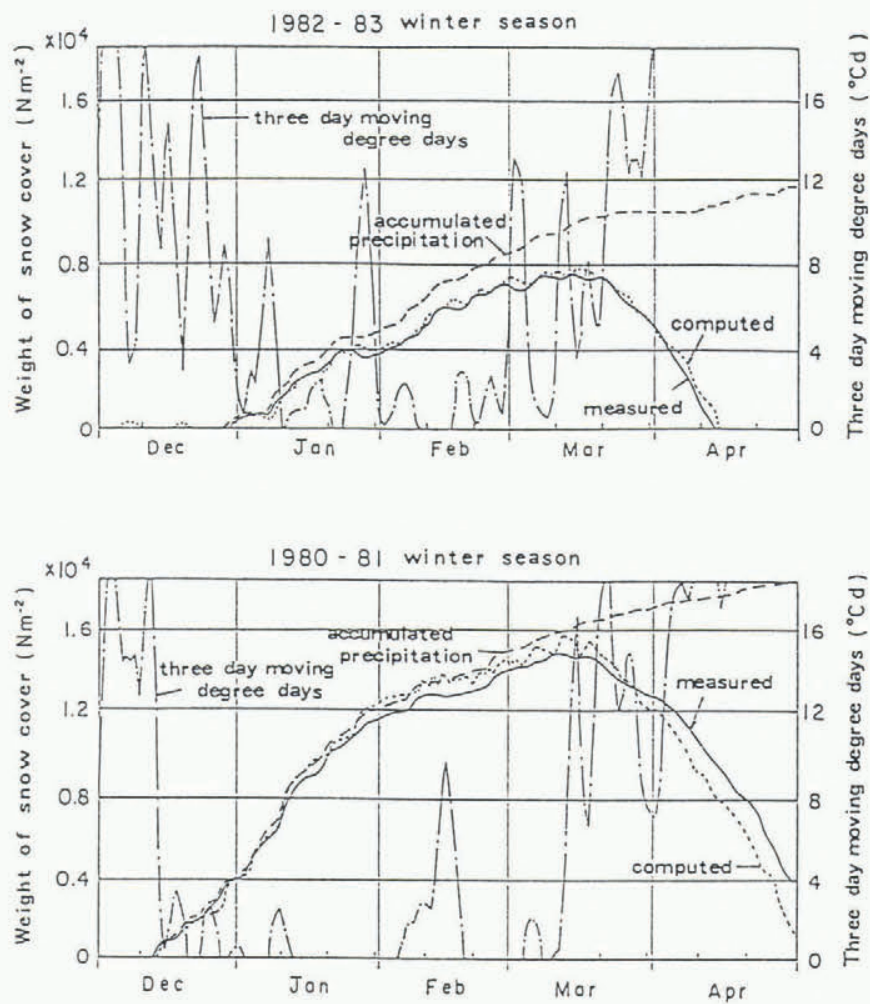

Fig. 2. Examples of the relation between estimated values and measurements observed at the Forestry and Forest Product Research Institute, Tokamachi Experiment Station (1982-83, light snow season; 1980-81, heavy snow season). 


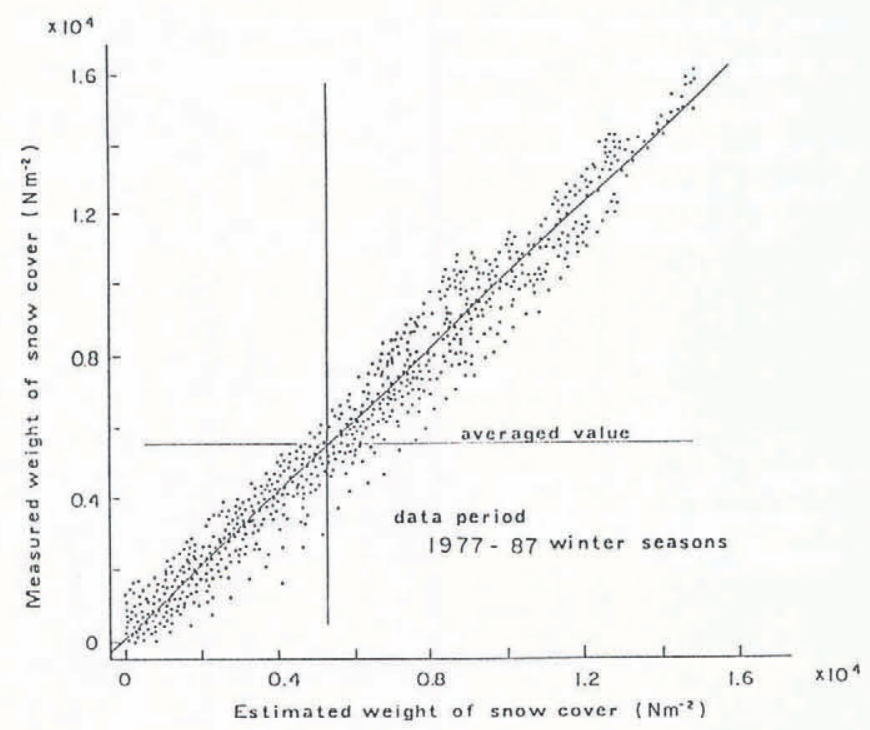

Fig. 3. Relation between daily measurements of the weight of snow cover observed at the Forestry and Forest Product Research Institute, Tokamachi Experiment Station, and daily estimated values through 11 winter seasons.

\section{RESULTS AND CONGLUSION}

By comparing the computed values using Equations (4) and (5) to the measured weights of the snow cover, good approximations could be obtained throughout the winter season.

Examples of the comparison of measured values with estimated results of the weight of the snow cover for a light snow season and a heavy snow season are shown in Figure 2. Further, Figure 3 shows the relationship between the measured values and the estimated results for daily data through the 11 winter seasons.

The coefficient of correlation among the groups of each value for 1323 days during the 11 winter seasons was 0.986 with a standard deviation of $\pm 590 \mathrm{~N} \mathrm{~m}^{-2}$. Thus, if the data on daily mean air temperatures and daily precipitation quantities can be obtained for an area, the daily weight of ground snow cover can be estimated with confidence.

The weight of snow on a roof may be estimated from data for the weight of snow cover on the ground. Snow amounts were measured on roofs and on the ground of nearby residences, comparing Aomori City in Aomori Prefecture and Tokamachi City in Niigata Prefecture for several winter seasons (December 1978-March 1991). As a result, it was found that roof snow was $60-80 \%$ of that on the ground even during snowfall periods, possibly due to partial snowmelt on roofs because of heat loss through the roof from the residence (Shinojima and Harada, 1992). Although these results are preliminary, we conclude that there is a good possibility of estimating the daily total weight of the snow cover where data exist for daily precipitation and daily mean air temperature.

\section{ACKNOWLEDGEMENT}

We wish to express appreciation to the Ministry of Agriculture, Forestry and Fishery's Forestry and Forest Product Research Institute, Tokamachi Experiment Station for permission to use their data.

\section{REFERENCES}

Hasemi, T. 1991. On a relation between probability occurrence of solid precipitation and ground air temperature (1). On the density of the relation and possibility of prediction of precipitation type. Seppyo. $\mathcal{F}$. Jpn. Soc. Snow Ice, 53(1), 33-43. [In Japanese with English summary.]

Ishikawa, N., K. Kojima and H. Motoyama. 1985. Predictions of hourly and daily amounts of snowmelt by heat balance or bulk meteorological elements. Low Temp. Sci., Ser. A 44, 63-75.

Kojima, K., H. Motoyama and Y. Yamada. 1983. Estimation of melting rate of snow by simple formulae using only air temperature. Low Temp. Sci., Ser. A 42, 101-110. [In Japanese with English summary.]

Kubota, H., H. Fukami, H. Ohmae, Y. Kaneda and T. Yamada. 1978. A study of snow melting in Mt. Asahidake, Hokkaido. Low Temp. Sci., Ser. A 36, 181188. [In Japanese with English summary.]

Shinojima, K. and H. Harada. 1992. A method for estimating the weight of snow cover on the ground and roofs using only items of AMeDAS's data. Fournal of Snow Engineering, 8(3), 191-205. [In Japanese with English summary.]

Takahashi, S., A. Sato and R. Naruse. 1981. A study of heat balance on the Yukikabe snow patch in the Daisetsu Mountains. Seppyo. F. Fpn. Soc. Snow Ice, 43(3), 147-154. [In Japanese with English summary.]

Tamura, M. 1990. Snow and rain fall frequencies in Nagaoka. Seppyo. J.Jpn. Soc. Snow Ice, 52(4), 251-257. [In Japanese with English summary.]

Tokamachi Experimental Site and Disaster Prevention Forest Laboratory. 1986. Data of properties of snow cover III. Dec. 1965-Apr. 197510 winter period. Bulletin of the Forestry and Forest Products Research Institute 341, 63-145.

Tokamachi Experimental Site and Disaster Prevention Forest Laboratory. 1987. Data of properties of snow cover IV. Dec. 1975-Apr. 198510 winter period. Bulletin of the Forestry and Forest Products Research Institute 342, 61-151.

The accuracy of references in the text and in this list is the responsibility of the authors, to whom queries should be addressed. 